\title{
Article
}

\section{Loneliness and Depression among Polish High-School Students}

\author{
Beata Dziedzic 1,*(D), Paulina Sarwa ${ }^{2} \mathbb{D}$, Ewa Kobos ${ }^{1}$, Zofia Sienkiewicz ${ }^{1}$, Anna Idzik ${ }^{1}(\mathbb{D}$, \\ Mariusz Wysokiński ${ }^{3}$ (D) and Wiesław Fidecki $^{3}$ (D)
}

1 Department of Nursing Development, Social and Medical Sciences, Faculty of Health Sciences, Medical University of Warsaw, Żwirki i Wigury 61, 02-091 Warsaw, Poland; ekobos@wum.edu.pl (E.K.); zofia.sienkiewicz@wum.edu.pl (Z.S.); anna.idzik@wum.edu.pl (A.I.)

2 Central Teaching Hospital of the Ministry of the Interior and Administration, Wołoska 137, 02-507 Warszawa, Poland; sarwapaulina96@gmail.com

3 Department of Basic Nursing and Medical Teaching, Chair of Development in Nursing, Faculty of Health Sciences, Medical University of Lublin, 20-081 Lublin, Poland; mariusz.wysokinski@umlub.pl (M.W.); wieslaw.fidecki@umlub.pl (W.F.)

* Correspondence: beata.dziedzic2@wum.edu.pl

Citation: Dziedzic, B.; Sarwa, P.; Kobos, E.; Sienkiewicz, Z.; Idzik, A.; Wysokiński, M.; Fidecki, W. Loneliness and Depression among Polish High-School Students. Int. J. Environ. Res. Public Health 2021, 18, 1706. https://doi.org/10.3390/ ijerph18041706

Academic Editor: Paul B. Tchounwou

Received: 5 January 2021

Accepted: 5 February 2021

Published: 10 February 2021

Publisher's Note: MDPI stays neutral with regard to jurisdictional claims in published maps and institutional affiliations.

Copyright: (c) 2021 by the authors. Licensee MDPI, Basel, Switzerland. This article is an open access article distributed under the terms and conditions of the Creative Commons Attribution (CC BY) license (https:/ / creativecommons.org/licenses/by/ $4.0 /)$.

\begin{abstract}
Introduction: Having impaired relations and limited interpersonal contact is associated with a sense of loneliness, and can result in a number of mental disorders, including the development of depression. Approximately one in five adolescents in the world suffers from depression, and first episodes of such are occurring at increasingly young ages. Due to a lack of appropriate support from parents, teachers and the healthcare system, the young person feels alone when dealing with their problem. Aims: The aims of this study are to determine the prevalence of anxiety, depression, aggression and sense of loneliness among high school students, and to analyze a correlation between loneliness and depression. Materials and methods: The study was conducted on 300 high school students in Poland. The study material was collected using the Hospital Anxiety and Depression Scale (HADS-M) and De Jong Gierveld Loneliness Scale (DJGLS). Results: A feeling of loneliness correlated significantly with depressive disorders $(p<0.005)$, with the strongest effect between the total HADS-M score and the total loneliness scale score $(r=0.61)$. The overall presence of disorders as per HADS-M was found to be $23 \%$, and borderline conditions were found in $19.3 \%$. In $24 \%$ of the students, disorders were revealed on the anxiety subscale and in $46.3 \%$ on the aggression subscale. On DJGLS, a very severe sense of loneliness was observed in $6.67 \%$ of the subjects, and in $42.3 \%$ of them, a moderate feeling of loneliness was indicated. On the social loneliness subscale, a severe sense of loneliness was found in $22.7 \%$, while on the emotional loneliness subscale, it was found in $16.7 \%$ of the subjects. Conclusions: In this study, a quarter of the student participants experienced anxiety and depression disorders. Students showing higher levels of anxiety, depression, and aggression also showed enhanced loneliness. Girls showed higher levels of anxiety, depression and aggression, as well as emotional loneliness.
\end{abstract}

Keywords: anxiety; depression; aggression; loneliness; teenagers

\section{Introduction}

According to the World Health Organization (WHO), adolescents account for 1.2 billion of the world's population [1], and 20\% of them suffer from mental health problems, with anxiety and depression being the most common [2]. Every year, 1.1 million young people die. The second most common cause of death in this age group is suicide and interpersonal violence. Undoubtedly, the occurrence of mental disorders and the associated mortality depends on age, gender and geography [1]. In addition, a number of factors that reduce the possibility of receiving quick help can cause such disorders to develop [1] and suicide rates to rise, the predictors of which can be depressive disorders $[3,4]$.

Herpertz-Dahlmann et al. showed that mental disorders such as depression, social anxiety, and eating disorders are more common in girls. Their prevalence ranges from 
$12 \%$ to $23 \%$, depending on the diagnostic instruments used. Disruptive disorders, e.g., disorders of social behavior, are more common in boys, with a worldwide prevalence of approximately $5 \%$ to $10 \%$ [5]. Bor et al. showed that one in five adolescents experienced mental health problems, again with a higher prevalence among girls [6].

The 2014 data for the European Union showed that symptoms of depression were observed in $4.8 \%$ of people in the age group of 15-19 years. The highest rates were reported for Iceland, Germany, Sweden, Ireland, Denmark, Luxembourg and Slovenia, respectively $(13.9 \%, 11 \%, 10.6 \%, 10.1 \%, 10 \%, 9.2 \%, 7.5 \%)$. In Poland, the percentage of adolescents with depressive disorders was $2.2 \%$ [7]. According to an analysis conducted by the Central Statistical Office of 5407 15-19-year-olds in Poland in 1996, one in ten experienced mental suffering [8]. Woynarowska et al. showed in their study in Poland that $25.2 \%$ of $15-16$-yearolds exceeded the thresholds of anxiety and depression justifying specialist consultation [9].

As indicated in the literature, mental health problems that begin at an early age may recur in adulthood [10]. The symptoms of childhood-onset anxiety and depression were also shown to continue later in life [11]. Some studies have shown that the incidence of depressive disorders increases from $4 \%$ at the age of 15 years to $16 \%$ at the age of 18 years [12]. Another study estimated an increase from $8.7 \%$ at the age of $13-14$ years to $15.7 \%$ at the age of $17-18$ years [13].

In a study evaluating the worldwide prevalence of depressive disorders, their low diagnosis rate was pointed out [14]. Early detection of the problem and the use of appropriate interventions are necessary to reduce its scale. Untreated abnormal states cause developmental disorders to deteriorate in young people, limiting their educational and life potential [15]. Progressing mental health problems have a negative impact on family relations, contact with friends and participation in social life. According to the WHO, young people with mental health problems are stigmatized in society and overlooked by healthcare systems [16]. For this reason, WHO strategies for its member states call for increased implementation of active measures for mental health; the theme of the 2018 World Mental Health Day was "Young People and Mental Health in the Changing World" [17].

Loneliness is a negative feeling that arises when a person's social needs are unmet by the quantity and quality of their social relationships [18]. It affects people of all ages, including children and adolescents [19]. In addition to the physical presence of another human being, a person needs relationships that will provide them with a sense of security, trust and belonging. In general, it is assumed that emotional loneliness refers to the absence of an attachment figure (together with feelings of isolation), and social loneliness to the lack of a social network, i.e., the absence of a circle of people that allows an individual to develop a sense of belonging, of company, of being part of a community [20].

Supportive social relationships are an indispensable part of good physical and mental wellbeing. Impaired relations can lead to the development of social loneliness [21]. For many years, authors of studies have pointed to the common prevalence of loneliness among the population [22,23], with higher rates generally reported among adolescents and young children, contrary to the myth that it is more common among older adults [24]. Qualitative data from interviews conducted in a group of $8-10$ year-olds have shown that $80 \%$ of these children experienced loneliness at school [25].

Loneliness is perceived as a deficit of social relations with regard to an individual's needs, which is associated with the progression of psychological processes such as depression and anxiety. This association is the strongest during puberty and leads to decreased function in both the physical and mental domains $[26,27]$. Loneliness is usually the consequence of limited interpersonal contact, while depression is characterized by a decreased mood and lack of satisfaction in all areas of everyday life. In individuals suffering from depressive disorders, loneliness is one of the accompanying symptoms. For this reason, depressive disorders are associated with a sense of loneliness [28].

Mahon et al., Vanhalst et al., and Lasgaard et al. showed that the level of loneliness increases with the severity of depression in adolescents [29-31]. However, studies on 
adolescents are scarce. This study was the first to additionally assess levels of aggression among students.

\section{Aim of the Study}

The aim of the study was to determine the prevalence of anxiety, depression, aggression and sense of loneliness among high school students, and to analyze the correlation between loneliness and depression.

\section{Materials and Methods}

\subsection{Participants}

This was a cross-sectional, descriptive study conducted in the period from October to December 2019 among 300 students of two Polish secondary schools located in one municipality. We used convenience sampling.

Participation in the study was voluntary and anonymous. The questionnaires used in the study, which included an explanation of the aim of the study and instructions on how to complete the forms, were distributed to 320 students during their lessons. The study analysis included 300 correctly completed questionnaires. The study population consisted of $63.0 \%$ of students aged $15-16$ years and $37.0 \%$ of students aged $17-18$ years. The mean age of participants was $\mathrm{M}=16.63$ years; $\mathrm{SD}=1.3$. Women accounted for $47.3 \%$ of the study group and men for $52.7 \%$. In the study group, $34 \%$ of the subjects came from urban areas and $66 \%$ came from rural areas.

Written consent of the schools' principals, the students and their parents was obtained for the study. The study was conducted in accordance with ethical principles and was based on informed consent of the participants, who had the right to withdraw from the study at any point without justification. The students' names were not provided in the questionnaire forms; thus, the data were anonymous.

\subsection{Instruments}

\subsubsection{Socio-Demographic Questionnaire}

The questionnaire asked about respondents' sociodemographic data, such as sex, age and place of residence.

\subsubsection{Hospital Anxiety and Depression Scale (HADS-M)}

In order to evaluate anxiety and depression, the Polish version of the Hospital Anxiety and Depression Scale (HADS-M) adapted by Majkowicz et al. was used [32], which is a modified version of the Hospital Anxiety and Depression Scale (HADS) developed by Zigmond and Snaith [33]. Validation of HADS among adolescents, as performed by White et al., showed that the depression subscale cut-off of 7 gave sensitivity 0.89 and specificity 0.66 ; an anxiety subscale cut-off of 9 gave sensitivity of 0.83 and specificity 0.47 [34]. In this study, the internal consistency of HADS-M was $a=0.65$ for anxiety subscale, $a=0.71$ for depression subscale and $a=0.59$ for aggression subscale. HADS contains two independent subscales: anxiety and depression; HADS-M includes two additional elements to assess aggression. HADS-M is composed of 16 questions in total; one can score from 0 to 3 points on each of them. The maximum score separately for anxiety (seven questions) and depression (seven questions) is 21 points, and the maximum score for aggression (two questions) is 6 points. A score in the range of 0-7 indicates a lack of disorders, a score in the range of 8-10 means a borderline state, while one in the range of 11-21 indicates the presence of disorders. The following interpretation was adopted in line with the questionnaire key for the anxiety and depression subscales: no disorders: 0-7 points, borderline states: 8-10 points, disorders: 11-21 points; the interpretation for the aggression subscale was: $0-2$ points: no disorders, 3 points: borderline states, 4-6 points: disorders. 


\subsubsection{De Jong Gierveld Loneliness Scale (DJGLS)}

In the study, the Polish version of the De Jong Gierveld Loneliness Scale (DJGLS) developed by De Jong Gierveld [35] was used. The Polish version was validated by Grygiel et al. [36,37]; it correlates with the UCLA Loneliness Scale $(r=0.82)$ and Beck Depression Inventory (BDI) $(r=0.46)$, among other measures. The reliability of DJGLS in the Polish adaptation was assessed using the internal consistency and homogeneity analysis, where the Cronbach alpha consistency level was obtained $(\alpha=0.89)$ [36]. In this study, the internal consistency of DJGLS was $\alpha=0.87$ for emotional loneliness, and $\alpha=0.86$ for social loneliness.

The scale includes 11 statements: 6 negative and 5 positive, regarding feelings associated with a lack of satisfaction with social contact and a lack of satisfaction with interpersonal relations. In this scale, two subscales were identified: emotional loneliness and social loneliness. Based on the interpretation of scores for the whole scale, the following categories of loneliness were defined: not lonely ( $0-2$ points); moderate loneliness (3-8 points); severe loneliness (9-10 points); very severe loneliness (11 points). On the emotional loneliness subscale, these include: not lonely ( $0-2$ points), moderately emotionally lonely (3-4 points) and severely emotionally lonely (5-6 points). On the social loneliness subscale, these include: not lonely ( $0-1$ point), moderately socially lonely ( $2-3$ points) and severely socially lonely ( $4-5$ points).

\subsection{Statistical Method}

The normality of data distribution was determined using the Shapiro-Wilk test and homogeneity of variance was checked with the Levene's test. Pearson's linear correlation coefficient $r$ and the Student's t-test for independent variables were applied. The significance level of $\alpha=0.05$ was adopted; the results were considered statistically significant if the calculated probability met the condition: $p \leq 0.05$. Calculations were performed using the Statistica 10.0 package by Statsoft Poland (Warsaw, Poland).

\section{Results}

Overall, on HADS-M, $23 \%$ of the students were found to have depressive disorders and were found to be $19.3 \%$ borderline abnormal. On the anxiety subscale, $24.0 \%$ were found to have disorders and $20.7 \%$ to be borderline abnormal; on the depression subscale, borderline abnormal was indicated for $13.3 \%$ of the subjects. The percentage of students with disorders on the aggression subscale was $46.3 \%$. Detailed results are presented in Table 1.

Table 1. Subjects' HADS-M scores.

\begin{tabular}{clcc}
\hline \multirow{3}{*}{ Anxiety subscale } & HADS-M & $n$ & $\%$ \\
\cline { 2 - 4 } & Norderline abnormal & 166 & 55.3 \\
\cline { 2 - 4 } & Presence of disorders & 62 & 20.7 \\
\hline \multirow{3}{*}{ Depression subscale } & No disorders & 236 & 24.0 \\
\cline { 2 - 4 } & Borderline abnormal & 40 & 78.6 \\
\cline { 2 - 4 } Aggression subscale & Presence of disorders & 24 & 13.3 \\
\cline { 2 - 4 } & No disorders & 113 & 8.0 \\
\cline { 2 - 4 } & Borderline abnormal & 48 & 37.7 \\
\cline { 2 - 4 } Total score & Presence of disorders & 139 & 16.0 \\
\hline & No disorders & 173 & 46.3 \\
\cline { 2 - 4 } & Borderline abnormal & 58 & 23.7 \\
\cline { 2 - 4 } & Presence of disorders & 69 & 19.3 \\
\hline
\end{tabular}


Our analysis revealed statistically significant differences between means of the total scores on HADS-M ( $p=0.002)$, anxiety subscale $(p<0.001)$ and aggression subscale $(p=0.001)$ with regard to the subjects' gender. Higher mean values were found for women. A statistically insignificant result was obtained for the depression subscale $(p=0.476)$ (Table 2).

Table 2. HADS-M scores with regard to the subjects' gender.

\begin{tabular}{cccccccc}
\hline \multirow{2}{*}{ HADS-M } & \multicolumn{2}{c}{ Men $(\boldsymbol{n}=\mathbf{1 5 8})$} & \multicolumn{2}{c}{ Women $(\boldsymbol{n = 1 4 2})$} & \multirow{2}{*}{$\boldsymbol{t}$} & \multirow{2}{*}{ df } & \multirow{2}{*}{$\boldsymbol{p}$} \\
\cline { 2 - 5 } & Mean & SD & Mean & SD & & & \\
\hline Anxiety & 6.58 & 4.28 & 8.51 & 4.45 & -3.81 & 298 & $<0.001$ \\
\hline Depression & 4.79 & 3.78 & 5.11 & 3.85 & -0.71 & 298 & 0.476 \\
\hline Aggression & 3.01 & 1.70 & 3.69 & 1.74 & -3.43 & 298 & 0.001 \\
\hline Total score & 14.38 & 8.01 & 17.30 & 8.59 & -3.05 & 298 & 0.002 \\
\hline
\end{tabular}

Our analysis did not reveal any statistically significant differences between means in the study group with regard to place of residence. This means that there was no evidence indicating that place of residence was a factor affecting the presence of anxiety, depression and aggression in the study group (Table 3).

Table 3. HADS-M scores with regard to place of residence.

\begin{tabular}{|c|c|c|c|c|c|c|c|}
\hline \multirow{2}{*}{ HADS-M } & \multicolumn{2}{|c|}{ Rural $(n=198)$} & \multicolumn{2}{|c|}{ Urban $(n=102)$} & \multirow{2}{*}{$t$} & \multirow{2}{*}{ df } & \multirow{2}{*}{$p$} \\
\hline & Mean & SD & Mean & SD & & & \\
\hline Anxiety & 7.66 & 4.52 & 7.18 & 4.35 & 0.88 & 298 & 0.378 \\
\hline Depression & 4.80 & 3.80 & 5.22 & 3.83 & -0.90 & 298 & 0.369 \\
\hline Aggression & 3.42 & 1.72 & 3.15 & 1.81 & 1.30 & 298 & 0.195 \\
\hline Total score & 15.88 & 8.67 & 15.54 & 7.90 & 0.33 & 298 & 0.741 \\
\hline
\end{tabular}

In total, on DJGLS, very severe loneliness was demonstrated for $6.7 \%$ of the students and severe loneliness for $7.7 \%$. On the emotional loneliness subscale, the percentage of students with severe loneliness (16.7\%) was slightly lower compared to the social loneliness subscale $(22.7 \%)$. Detailed results are presented in Table 4.

Table 4. Subjects' DJGLS scores.

\begin{tabular}{clccc}
\hline DJGLS & & $\boldsymbol{n}$ & \% \\
\hline \multirow{3}{*}{ Emotional loneliness subscale } & Not lonely & 187 & 62.5 \\
\cline { 2 - 4 } & Moderate loneliness & 63 & 21.0 \\
\cline { 2 - 4 } & Severe loneliness & 50 & 16.7 \\
\hline \multirow{3}{*}{ Social loneliness subscale } & Not lonely & 144 & 48.0 \\
\cline { 2 - 4 } & Moderate loneliness & 88 & 29.3 \\
\cline { 2 - 4 } & Severe loneliness & 68 & 22.7 \\
\cline { 2 - 4 } Total score & Not lonely & 130 & 43.3 \\
\cline { 2 - 4 } & Moderate loneliness & 127 & 42.3 \\
\cline { 2 - 4 } & Severe loneliness & 23 & 7.7 \\
\cline { 2 - 4 } & Very severe loneliness & 20 & 6.7 \\
\hline
\end{tabular}

Statistically significant differences between means with regard to gender were found only for the emotional loneliness subscale $(p=0.008)$. Women scored higher on this 
subscale. A statistically insignificant result was obtained for the second component, the social loneliness scale $(p=0.514)$ (Table 5).

Table 5. DJGLS scores with regard to gender.

\begin{tabular}{cccccccc}
\hline \multirow{2}{*}{ DJGLS } & \multicolumn{2}{c}{ Men $(\boldsymbol{n}=\mathbf{1 5 8})$} & \multicolumn{2}{c}{ Women $(\boldsymbol{n}=\mathbf{1 4 2})$} & $\boldsymbol{t}$ & $\mathrm{df}$ & $\boldsymbol{p}$ \\
\cline { 2 - 8 } & Mean & SD & Mean & SD & & & \\
\hline Emotional loneliness & 1.77 & 2.00 & 2.41 & 2.14 & -2.69 & 298 & 0.008 \\
\hline Social loneliness & 1.85 & 1.86 & 1.99 & 1.78 & -0.65 & 298 & 0.514 \\
\hline Total loneliness score & 3.61 & 3.48 & 4.39 & 3.58 & -1.91 & 298 & 0.057 \\
\hline
\end{tabular}

A statistical analysis did not reveal any statistically significant differences between means on DJGLS in the study group with regard to place of residence $(p=0.292)$ (Table 6 ).

Table 6. DJGLS scores with regard to place of residence.

\begin{tabular}{cccccccc}
\hline \multirow{2}{*}{ DJGLS } & \multicolumn{2}{c}{ Rural $(\boldsymbol{n}=\mathbf{1 9 8})$} & \multicolumn{2}{c}{ Urban $(\boldsymbol{n = 1 0 2})$} & \multirow{2}{*}{$\boldsymbol{t}$} & \multirow{2}{*}{ df } & \multirow{2}{*}{$\boldsymbol{p}$} \\
\cline { 2 - 6 } & Mean & SD & Mean & SD & & & \\
\hline Emotional loneliness & 1.99 & 2.11 & 2.22 & 2.05 & -0.87 & 298 & 0.386 \\
\hline Social loneliness & 1.83 & 1.78 & 2.07 & 1.90 & -1.06 & 298 & 0.290 \\
\hline Total loneliness score & 3.83 & 3.49 & 4.28 & 3.63 & -1.06 & 298 & 0.292 \\
\hline
\end{tabular}

Our analysis demonstrated statistically significant positive correlations between HADS-M and DJGLS scores. Increasing loneliness scores were accompanied by increasing anxiety, depression and aggression scores. The highest strength of effect was found between two overall indicators: the total HADS-M score and the total loneliness scale score $(r=0.61)$. The $r$ values between the different subscales were diverse, ranging from weak associations $(r=0.26)$ to strong associations $(r=0.57)$. The results are presented in Table 7 .

Table 7. Correlations between sense of loneliness and anxiety, depression and aggression.

\begin{tabular}{ccccc}
\hline \multirow{2}{*}{ DJGLS } & \multicolumn{4}{c}{ HADS-M } \\
\cline { 2 - 5 } & Anxiety & Depression & Aggression & Total Score \\
\hline \multirow{2}{*}{ Emotional loneliness } & $r=0.55$ & $r=0.49$ & $r=0.27$ & $r=0.57$ \\
\cline { 2 - 5 } & $p<0.001$ & $p<0.001$ & $p<0.001$ & $p<0.001$ \\
\hline \multirow{2}{*}{ Social loneliness } & $r=0.47$ & $r=0.52$ & $r=0.26$ & $r=0.54$ \\
\cline { 2 - 5 } & $p<0.001$ & $p<0.001$ & $p<0.001$ & $p<0.001$ \\
\hline \multirow{2}{*}{ Total score } & $r=0.57$ & $r=0.55$ & $r=0.29$ & $r=0.61$ \\
\cline { 2 - 5 } & $p<0.001$ & $p<0.001$ & $p<0.001$ & $p<0.001$ \\
\hline
\end{tabular}

\section{Discussion}

The present study was conducted to determine the prevalence of anxiety, depression, aggression and sense of loneliness among high school students, and to analyze the correlations among loneliness, anxiety and depression. Undoubtedly, attention should be paid to the essence of the problem, which is depression and loneliness among adolescents, and the consequences of delayed or missed diagnosis. For adolescents, monitoring the problem and sufficiently early implementation of support strategies represent a chance to minimize the consequences [38]. For our study, we selected a group of young people who were entering adulthood, were at a stage of many changes and were searching for their own identity. In some adolescents, the associated sense of anxiety and uncertainty as a 
result of those changes can contribute to the development of mental problems, affecting progression in adulthood, which is consistent with previous research [39-41].

The current study demonstrated a higher percentage of adolescents with depressive disorders compared to research by other authors [2,5,7,8]; additionally, it was shown that loneliness was correlated with the frequency of anxiety and depressive disorders [25,28], which were more common in girls $[5,6]$.

The significant correlation between loneliness and the rate of depressive disorders demonstrated in our study is corroborated by the research of other authors [28,42]. In a study by Sahin et al., conducted on high school students, a higher level of loneliness was found in men than women, in contrast to our results. This difference may be due to different living conditions and cultural differences between Turkey and European countries [42].

Shevlin et al. assessed the impact of loneliness on the development of mental disorders in teenagers in Northern Ireland. They found that loneliness, which was present in $15.6 \%$ of the subjects, correlated significantly with mental problems and was more common in females. According to the authors, the risk of mental disorders in individuals with a known sense of loneliness increased as much as five-fold [27]. Our study presented similar findings in terms of loneliness scores, and found this variable to be higher in women.

Ebesutani et al. obtained different results regarding the level of loneliness and depression symptoms in a large sample of American adolescents compared to the results of the present study. They demonstrated that $16.8 \%$ of adolescents were in an increased score range for depression, $28.7 \%$ for loneliness and $9.1 \%$ for anxiety. According to the authors of that study, loneliness was a significant predictor of depressive disorders [43]. A study conducted in Norway which aimed to determine a trend in the frequency of symptoms of anxiety, depression and sense of loneliness among adolescents, demonstrated an increase in high depressive symptom loads of up to $73 \%$ in a group of girls, and up to $46 \%$ in a group of boys. Likewise, the frequency of high anxiety symptom scores increased to $42 \%$ in girls and $17 \%$ in boys. Severe loneliness was noted in $15 \%$ of girls and $9 \%$ of boys [44].

Compared to the results of a study by Diehl et al., the current study demonstrated a higher total sense of loneliness score and higher scores on both subscales. Overall, in the study by Diehl et al., moderate loneliness was experienced by $32.4 \%$ of the subjects and very severe loneliness by $3.2 \%$. On the emotional loneliness subscale, $7.7 \%$ of the subjects were shown to be severely lonely, and on the social loneliness subscale, $3.2 \%$ were rated as such. Similar to our study, the authors demonstrated a correlation between loneliness and depression. The differences in scores between the two studies may be due to an age difference. In the study by Diehl et al., the participants were aged 16-29 years. That study was one of the few in which DJGLS was used for the assessment of loneliness [21]. Similar to us, Diehl et al. and the authors of a study on a group of girls aged 15-18 years demonstrated a positive correlation between loneliness and degree of anxiety and depression [45].

Correlation of loneliness on intensity of depression is consistent with the findings of many authors [29-31,46], with a significant proportion of studies focusing on the correlation between sense of loneliness and depressive disorders. In a study by Lasgaard et al. conducted on a group of 1009 high school students, a hypothesis was put forward whereby loneliness correlates with the development of symptoms of depression depending on the source of loneliness, and a mutual correlation was demonstrated. Loneliness and depression turned out to be more common in girls, as confirmed in our study. It was demonstrated that peer- and family-related loneliness was associated with depression, anxiety and suicidal thoughts [29]. Similar conclusions were made in a study by Bračič et al. conducted in Slovenia, in which higher loneliness and depressive disorder indicators in adolescents additionally resulted in an increased suicide rate (15.5\%) [46]. Vanhalst et al. also pointed to a mutual dependence between loneliness and depression from middle to late puberty [30]. Our findings showed the strength of the association between loneliness and depression to be $r=0.61$, which was confirmed in a finding from a meta-analysis by 
Mahon et al., in which the correlation between depression and loneliness also had a high strength of effect [31].

A study by Polish authors Dymowska and Nowicka-Sauer, based on the Primary Care Evaluation of Mental Disorders questionnaire, showed that depressive disorders are present in $25.7 \%$ of 18 -year-olds [47]. In our study, a similar rate was observed, while the percentage of young people with borderline states was higher. The prevalence of depression symptoms among adolescents was confirmed in a study by Modrzejewska and Bomba [48]. Two groups of adolescents were studied: one in 1984 and the other in 2001. In the first study (1984), depressive disorders were found in $20.8 \%$ of boys and $32.2 \%$ of girls. In the second study (2001), the Kraków Depression Inventory (KID) was used, which showed that $19.1 \%$ of boys and $34.9 \%$ of girls had depressive disorders; in addition, the Beck Depression Inventory (BDI) was used, according to which $18.2 \%$ of boys and $33.6 \%$ of girls had symptoms of depression. Similar to this study, there was a striking finding in a study by Wiklund et al. [49] of a high prevalence of anxiety, both among boys and girls, with a higher prominence in girls. Compared to a group of high school girls in a study by Blom et al. [50], the girls in our study had a higher mean level of anxiety. According to the authors, $31.5 \%$ of girls had borderline anxiety and $27 \%$ had anxiety disorders compared to $21.1 \%$ of boys with borderline anxiety and $8.7 \%$ with disorders on the anxiety subscale. Scores on the depression subscale were lower than for anxiety, and gender differences in the level of depression were small and insignificant.

When validating HADS, the original version of HADS-M, on a group of adolescents in Hong Kong, Chan et al. demonstrated the presence of clinically significant anxiety in $30.0 \%$ of subjects aged 10-19 years and clinically significant depression in $34 \%$ of them. HADS displayed satisfactory psychometric properties as a screening tool for anxiety and depression in a group of adolescents [51].

When comparing the results of the present study with those of other authors, it needs to be emphasized that different research tools were used in the majority of those studies. Out literature review indicated that no existing data that would make a precise comparison possible. Few studies have been conducted using the scales applied in the present study. A small number of students took part in the present study, and convenience sampling was used, which means that only available students were included. Despite this limitation, our study shows that the scale of the problem is substantial. In Poland, few studies have been carried out to assess the level of depression and loneliness among teenagers. These findings showed that loneliness was positively correlated with depression. This study was the first to additionally assess the level of aggression among students. Our study indicates the importance of screening tests for young people.

\section{Conclusions}

In this study, depression and loneliness symptoms were identified in a substantial proportion of the students, and a positive correlation between loneliness and depression was found.

Anxiety and depressive disorders were demonstrated in one in four students. Girls showed higher levels of anxiety, depression and aggression, and higher emotional loneliness.

Early identification of adolescents experiencing loneliness and anxiety and depressive disorders is an important task for parents, teachers and healthcare professionals.

Author Contributions: Conceptualization, B.D. and P.S.; data curation, E.K. and W.F.; formal analysis, B.D., P.S., W.F., and M.W.; investigation, B.D., A.I., E.K., and M.W.; methodology, B.D., Z.S., and A.I.; project administration, B.D. and Z.S.; resources, B.D.; supervision, B.D.; writing一 original draft, B.D., Z.S., A.I., E.K., W.F., and M.W.; and writing—review \& editing, B.D., P.S., and Z.S. All authors have read and agreed to the published version of the manuscript.

Funding: This research received no external funding.

Institutional Review Board Statement: Research has been performed in accordance with the Declaration of Helsinki. It was voluntary for the high school students to answer the questionnaires, and 
they had the right to withdraw their participation at any time. All the answers were treated as strictly confidential, and the high school students were guaranteed full anonymity. Oral informed consent to participate in the study was obtained from the subjects. The study was approved by the Bioethics Committee at the Medical University of Warsaw (approval No. AKBE/217/2020).

Informed Consent Statement: Informed consent was obtained from all subjects involved in the study.

Data Availability Statement: The datasets generated and/or analyzed during the current study are not publicly available due to confidentiality, but data is accessible from the corresponding author on reasonable request.

Limitations of the Study: Our study had certain limitations. This study took place only in two school, thus limiting the generalization of these results to other centers in Poland. A small number of pupils took part in the study, convenience sampling was used, which means that only available pupils were included in the study. The data for analysis were obtained at a single time point; thus, no trends regarding the development of the disorders mentioned above and possible contributing factors were investigated. The analyses did not consider the family context and socioeconomic status. The differences between the results of our study and those of other studies may be due to methodological considerations associated with the use of different scales.

Conflicts of Interest: The authors declare no conflict of interest.

\section{References}

1. World Health Organization. Health Topics. Available online: https://www.who.int/health-topics/adolescent-health (accessed on 6 November 2020).

2. World Health Organization. Mental Health. Available online: https://www.who.int/health-topics/mental-health (accessed on 6 November 2020).

3. Galaif, E.R.; Sussman, S.; Newcomb, M.D.; Locke, T.F. Suicidality, depression, and alcohol use among adolescents: A review of empirical findings. Int. J. Adolesc. Med. Health. 2007, 19, 27-35. [CrossRef] [PubMed]

4. Hawton, K.; Saunders, K.; Topiwala, A.; Haw, C. Psychiatric disorders in patients presenting to hospital following self-harm: A systematic review. J. Affect. Disord. 2013, 151, 821-830. [CrossRef]

5. Herpertz-Dahlmann, B.; Bühren, K.; Remschmidt, H. Growing up is hard. Mental disorders in adolescents. Dtsch. Arztebl. Int. 2013, 110, 432-440. [PubMed]

6. Bor, W.; Dean, A.; Najman, J.; Hayatbakhsh, R. Are Child and Adolescent Mental Health Problems Increasing in the 21st Century? A Systematic Review. Aust. N. Z. J. Psychiatry 2014, 47, 606-616. [CrossRef]

7. Eurostat. Current Depressive Symptoms by Sex, Age and Educational Attainment Level. Available online: http:/ / appsso.eurosta t.ec.europa.eu/nui/submitViewTableAction.do (accessed on 6 November 2020).

8. Tabak, I.; Ostrega, W.; Biernacka, B.; Jodkowska, M. Subjective health complaints and psychological distress in adolescents aged 15-19 years in Poland. Dev. Med. 2004, 8, 585-894.

9. Mazur, J.; Nałęcz, H.; Kleszczewska, D.; Małkowska-Szkutnik, A.; Borraccino, A. Behavioural factors enhancing mental healthPreliminary results of the study on its association with physial activity in 15 to 16 year olds. Dev. Period Med. 2016, 20, 315-324. [PubMed]

10. Marcus, M.; Yasamy, T.M.; van Ommeren, M.; Chisholm, D.; Saxena, S. Depression: A Global Public Health Concern; World Health Organization. Department of Mental Health and Substance Abuse: Geneva, Switzerland, 2012.

11. Kolaitis, G. Mood disorders in childhood and adolescence: Continuities and discontinuities to adulthood. Psychiatrike 2012, 23, 94-100. [PubMed]

12. Jaffee, S.R.; Moffitt, T.E.; Caspi, A.; Fombonne, E.; Poulton, R.; Martin, J. Differences in early childhood risk factors for juvenileonset and adult-onset depression. Arch. Gen. Psychiatry 2002, 58, 215-222. [CrossRef] [PubMed]

13. Merikangas, K.R.; He, J.P.; Burstein, M.; Swanson, S.A.; Avenevoli, S.; Cui, L.; Benjet, C.; Georgiades, K.; Swendsen, J. Lifetime prevalence of mental disorders in US adolescents: Results from the National Comorbidity Study-Adolescent Supplement (NCS-A). J. Am. Acad. Child Adolesc. Psychiatry 2010, 49, 980-989. [CrossRef] [PubMed]

14. Thapar, A.; Collishaw, S.; Pine, D.S.; Thapar, A.K. Depression in adolescence. Lancet 2012, 17, 379. [CrossRef]

15. Cheung, A.H.; Kozloff, N.; Sacks, D. Pediatric depression: An evidence-based update on treatment interventions. Curr. Psychiatry Rep. 2013, 15, 381. [CrossRef] [PubMed]

16. World Health Organization. Mental Health. Available online: https://www.who.int/mental_health/maternal-child/en/ (accessed on 6 November 2020).

17. World Health Organization. Mental Health and Substance Use. Available online: https://www.who.int/mental_health/ (accessed on 6 November 2020).

18. Perlman, D.; Peplau, L.A. Toward a Social Psychology of Loneliness. In Personal Relationships in Disorder; Duck, S., Gilmour, R., Eds.; Academic Press: London, UK, 1991; pp. 31-56. 
19. Qualter, P.; Vanhalst, J.; Harris, R.A.; Van Roekel, E.; Lodder, G.; Bangee, M.; Verhagen, M. Loneliness across the life span. Perspect. Psychol. Sci. 2015, 10, 250-264. [CrossRef] [PubMed]

20. Yanguas, J.; Pinazo-Henandis, S.; Tarazona-Santabalbina, F.J. The complexity of loneliness. Acta Biomed. 2018, 89, 302-314. [CrossRef] [PubMed]

21. Diehl, K.; Jansen, C.; Ishchanova, K.; Hilger-Kolb, J. Loneliness at Universities: Determinants of Emotional and Social Loneliness among Students. Int. J. Environ. Res. Public Health. 2018, 29, 1865. [CrossRef] [PubMed]

22. Weeks, D.J. A review of loneliness concepts, with particular reference to old age. Int. J. Geriatr. Psychiatry 1994, 9, 345-355. [CrossRef]

23. West, D.A.; Kellner, R.; Moore-West, M. The Effects of Loneliness: A Review of the Literature. Compr. Psychiatry 1986, 27, 351-383. [CrossRef]

24. Mushtaq, R.; Shoib, S.; Shah, T.; Mushtaq, S. Relation between Loneliness, Psychiatric Di-sorders and Physical Health? A Review on the Psychological Aspects of Loneliness. J. Clin. Diagn. Res. 2014, 8, 1-3.

25. Berguno, G.; Leroux, P.; McAinsh, K.; Shaikh, S. Children's experience of loneliness at school and its relation to bullying and the quality of teacher interventions. Qual. Rep. 2004, 9, 483-499.

26. Hawkley, L.C.; Cacioppo, J.T. Loneliness matters: A theoretical and empirical review of consequences and mechanisms. Ann. Behav. Med. 2010, 40, 218-227. [CrossRef]

27. Shevlin, M.; Murphy, S.; Mallett, J.; Stringer, M.; Murphy, J. Adolescent loneliness and psychiatric morbidity in Northern Ireland. Br. J. Clin. Psychol. 2013, 52, 230-234. [CrossRef]

28. Erzen, E.; Cikrikci, O. The effect of loneliness on depression: A meta-analysis. Int. J. Soc. Psychiatry 2018, 64, 427-435. [CrossRef]

29. Lasgaard, M.; Goossens, L.; Bramsen, R.; Trillingsgaard, T.; Elklit, A. Different sources of loneliness are associated with different forms of psychopathology in adolescence. J. Res. Personal. 2011, 45, 233-237. [CrossRef]

30. Vanhalst, J.; Klimstra, T.; Luyckx, K.; Scholte, R.; Engels, R.; Goossens, L. The interplay of loneliness and depressive symptoms across adolescence: Exploring the role of personality traits. J. Youth Adolesc. 2012, 41, 776-787. [CrossRef]

31. Mahon, N.E.; Yarcheski, A.; Yarcheski, T.J.; Cannella, B.L.; Hanks, M.M. A Meta-analytic Study of Predictors for Loneliness During Adolescence. Nurs. Res. 2006, 55, 308-315. [CrossRef]

32. Majkowicz, M. Practical assessment of palliative care efficacy: Selected research techniques. In Evaluation of Palliative Care Quality in Theory and Practice; de Walden-Gałuszko, K., Majkowicz, M., Eds.; Akademia Medyczna: Gdańsk, Poland, 2000.

33. Zigmond, A.S.; Snaith, R.P. The Hospital Anxiety and Depression Scale. Acta Psychiatry Scand. 1983, 67, 361-370. [CrossRef] [PubMed]

34. White, D.; Leach, C.; Sims, R.; Atkinson, M. Cottrell, D. Validation of the Hospital Anxiety and Depression Scale for use with adolescents. Br. J. Psychiatry 1999, 175, 452-454. [CrossRef]

35. De Jong Gierveld, J.; Van Tilburg, T.G. Manual of the Loneliness Scale; VU University: Amsterdam, The Netherlands, 1999.

36. Grygiel, P.; Humenny, G.; Rębisz, S.; Świtaj, P.; Sikorska-Grygiel, J. Validating the Polish adaptation of the 11-item De Jong Gierveld Loneliness Scale. Eur. J. Psychol. Assess. 2013, 29, 129-139. [CrossRef]

37. Grygiel, P.; Humenny, G.; Rębisz, S. Using the De Jong Gierveld Loneliness Scale With Early Adolescents: Factor Structure, Reliability, Stability, and External Validity. Assessment 2019, 26, 151-165. [CrossRef] [PubMed]

38. Ma, T.L.; Chow, C.M.; Chen, W.T.J. The moderation of culturally normative coping strategies on Taiwanese adolescent peer victimization and psychological distress. Sch. Psychol. 2018, 70, 89-104. [CrossRef] [PubMed]

39. Van Droogenbroeck, F.; Spruyt, B.; Keppens, G. Gender differences in mental health problems among adolescents and the role of social support: Results from the Belgian health interview surveys 2008 and 2013. BMC Psychiatry 2018, 18, 6. [CrossRef]

40. Marmorstein, N.R.; Iacono, W.G. Major depression and conduct disorder in a twin sample: Gender, functioning, and risk for future psychopathology. J. Am. Acad. Child Adolesc. Psychiatry 2003, 42, 225-233. [CrossRef]

41. Zoccolillo, M. Co-occurrence of conduct disorder and its adult outcomes with depressive and anxiety disorders: A review. J. Am. Acad. Child Adolesc. Psychiatry 1992, 31, 547-556. [CrossRef]

42. Sahin, U.; Adana, F. Problem solving, loneliness, depression levels and associated factors in high school adolescents. Pak. J. Med. Sci. 2016, 32, 1273-1278. [CrossRef] [PubMed]

43. Ebesutani, C.; Fierstein, M.; Viana, A.G.; Trent, L.; Young, J.; Sprung, M. The role of loneliness in the relationship between anxiety and depression in clinical and school-based youth. Psychol. Sch. 2015, 52, 223-234. [CrossRef]

44. Myhr, A.; Anthun, K.S.; Lillefjell, M.; Sund, E.R. Trends in Socioeconomic Inequalities in Norwegian Adolescents' Mental Health from 2014 to 2018: A Repeated Cross-Sectional Study. Front Psychol. 2020, 11, 1472. [CrossRef]

45. Majd, A.E.; Talepasand, S.; Rezaei, A.A. Structural Model of Depression Based on Interpersonal Relationships: The Mediating Role of Coping Strategies and Loneliness. Arch. Psikiyatr. 2017, 54, 125-130. [CrossRef]

46. Bračič, M.; Roškar, S.; Zager, K.G.; Jeriček, K.H. The Prevalence and Predictors of Suicidal Ideation among Slovene Adolescents. Community Ment. Health J. 2019, 55, 1210-1217. [CrossRef] [PubMed]

47. Dymowska, A.; Sauer, N. Depression among adolescents-Still actual problem. Family Med. Forum. 2015, 2, 124-126.

48. Modrzejewska, R.; Bomba, J. A comparative study of adolescent depression among high school pupils in a large Polish city. Arch. Psychiatry Psychother. 2010, 2, 17-22. 
49. Wiklund, M.; Malmgren-Olsson, E.B.; Öhman, A.; Bergström, E.; Fjellman-Wiklund, A. Subjective health complaints in older adolescents are related to perceived stress, anxiety and gender-A cross-sectional school study in Northern Sweden. BMC Public Health. 2012, 12, 993. [CrossRef] [PubMed]

50. Blom, E.H.; Larsson, J.O.; Serlachius, E.; Ingvar, M. The differentiation between depressive and anxious adolescent females and controls by behavioural self-rating scales. J. Affect Disord. 2010, 122, 232-240. [CrossRef] [PubMed]

51. Chan, Y.F.; Leung, D.Y.; Fong, D.Y.; Leung, C.M.; Lee, A.M. Psychometric evaluation of the Hospital Anxiety and Depression Scale in a large community sample of adolescents in Hong Kong. Qual. Life Res. 2010, 19, 865-873. [CrossRef] [PubMed] 